\title{
Níveis de salinidade e manejo da fertirrigação sobre características da berinjela cultivada em ambiente protegido ${ }^{1}$
}

\author{
Levels of salinity and fertigation management on the characteristics of the eggplant \\ when grown in a protected environment
}

\author{
Everaldo Moreira da Silva ${ }^{2 *}$, Carlos José Gonçalves de Souza Lima ${ }^{3}$, Sergio Nascimento Duarte ${ }^{3}$, Fernando da \\ Silva Barbosa ${ }^{3}$ e Rafael Maschio ${ }^{3}$
}

\begin{abstract}
RESUMO - Objetivou-se estudar os efeitos de diferentes níveis de salinidade do solo sobre as variáveis fenológicas e de produção da berinjela, cultivada em vasos e em ambiente protegido. O estudo foi conduzido na área experimental do Departamento de Engenharia de Biossistemas da ESALQ/USP, Piracicaba, SP. Os tratamentos foram compostos da combinação de dois fatores: 6 níveis de salinidade inicial do solo $(\mathrm{S} 1=1,3 ; \mathrm{S} 2=2,4 ; \mathrm{S} 3=3,6 ; \mathrm{S} 4=4,5 ; \mathrm{S} 5=5,6$ e $\mathrm{S} 6=6,4 \mathrm{dS} \mathrm{m}^{-1}$ ) e dois manejos de fertirrigação: com controle da condutividade elétrica da solução do solo (M1), e o tradicional (M2), obedecendo a curva de absorção de nutrientes da cultura. O delineamento estatístico adotado foi o de blocos casualizados completos, com quatro repetições, arranjados no esquema fatorial 6 x 2. Os resultados revelaram que os níveis de salinidade do solo afetaram diretamente as variáveis, produção de matéria seca, produção de frutos e índice de área foliar das plantas. Verificou-se que a redução média na produção da cultura da berinjela, em estufa, foi da ordem de $8,65 \%$ para o incremento de $1 \mathrm{dS} \mathrm{m}^{-1}$ na salinidade do solo, acima da salinidade limiar, que foi de $1,71 \mathrm{dS} \mathrm{m}^{-1}$.
\end{abstract}

Palavras-Chave: Berinjela. Solos-salinidade. Adubos e fertilizantes.

\begin{abstract}
The objective was to study the effects of different levels of soil salinity on the phenological variables and production of the eggplant when grown in pots in a protected environment. The study was carried out at the experimental site of the Department of Biosystems Engineering ESALQ/USP in Piracicaba, São Paulo. The treatments consisted of a combination of two factors: six initial levels of soil salinity $(\mathrm{S} 1=1.3, \mathrm{~S} 2=2.4, \mathrm{~S} 3=3.6, \mathrm{~S} 4=4.5, \mathrm{~S} 5=5.6$ and $\mathrm{S} 6=$ $6.4 \mathrm{dS} \mathrm{m}^{-1}$ ) and two fertigation management: with the electrical conductivity of the soil solution being controlled (M1) and traditional (M2), following the absorption curve of nutrients from the culture. The statistical design adopted was a randomized complete-block design with four replications, arranged in a 6 x 2 factorial. The results showed that the levels of soil salinity directly affected the variables of dry-matter production, fruit production and leaf-area index of the plants. It was found that the average reduction in yield of the eggplant crop in a greenhouse, was approximately $8.65 \%$ for an increase of $1 \mathrm{dS} \mathrm{m}^{-1}$ in the salinity of the soil above the threshold salinity of $1.71 \mathrm{dS} \mathrm{m}^{-1}$.
\end{abstract}

Key words: Eggplant. Soil-salinity. Manure-fertilizers.

\footnotetext{
*Autor para correspondência

${ }^{1}$ Recebido para publicação em 23/02/2011; aprovado em 12/07/2012

Parte da Dissertação de Mestrado do primeiro autor, apresentada ao Programa de Pós-Graduação em Irrigação e Drenagem - ESALQ/USP; Pesquisa financiada pela FAPESP

${ }^{2}$ Departamento de Engenharia de Biossistemas, ESALQ/USP, Av. Pádua Dias, 11, Piracicaba-SP, Brasil, 13.418-900, everaldo@usp.br

${ }^{3}$ Departamento de Engenharia de Biossistemas, ESALQ/USP, Piracicaba-SP, Brasil, cjgslima@usp.br, snduarte@esalq.usp.br, fernandosb@ usp.br ,rafaelmaschio@usp.br
} 


\section{INTRODUÇÃO}

A berinjela (Solanum melongena L.) é uma solanácea de ciclo anual, originária das regiões tropicais do Oriente, sendo cultivada há séculos por chineses e árabes (ANTONINI et al., 2002). A planta apresenta hábito arbustivo, com caule semilenhoso, e pode alcançar altura superior a um metro. Apresenta ramificações bem desenvolvidas, sistema radicular profundo, com flores hermafroditas, violáceas, com 4 a $5 \mathrm{~cm}$ de diâmetro, às vezes com uma pequena mancha amarela e baixa incidência de polinização cruzada; possui cálice verde e coberto por pêlos (FILGUEIRA, 2000).

Atualmente, é cultivada em aproximadamente 1.500 ha no Brasil, e com demanda crescente, devido às propriedades medicinais dos frutos, como redução do nível de colesterol, e por representarem boa fonte de sais minerais e vitaminas (GONÇALVES et al., 2006). Assim como várias hortaliças, tem sido produzida em condições de cultivo protegido, o qual possibilita um abastecimento contínuo e colheitas em períodos de baixa oferta do produto no mercado, alcançando, por isso, preços mais competitivos (MAGGI et al., 2006). Porém, existem muitos problemas relacionados à adubação excessiva, levando o solo a um acúmulo de sais no solo e perca de nutrientes por percolação profunda (CARDOSO et al., 2008).

Marques (2003) estudou o efeito da salinização nos componentes de rendimento da berinjela no município de Lavras - MG, e verificou que a salinidade na água de irrigação reduz a produção total da cultura e a produção comercial. Moura, Carvalho e Gomes (2004) notaram, em estudo com a irrigação com água salina na cultura da berinjela, que a evapotranspiração da cultura diminui linearmente com o aumento da concentração de sais na água de irrigação e, ainda, que a produção da cultura é afetada pelo déficit hídrico.

De acordo Unlukara et al. (2008) a berinjela é classificada como moderadamente sensível à salinidade, com queda no rendimento a partir de $1,5 \mathrm{dS} \mathrm{m}^{-1}$ de condutividade elétrica da água de irrigação com uma perda de produtividade de $4,4 \%$ para cada aumento unitário de condutividade elétrica.

Por outro lado, Bosco et al. (2009) ao estudar níveis crescentes de condutividade elétrica obtidos pela adição de $\mathrm{NaCl}$ à solução nutritiva no cultivo hidropônico de berinjela cultivar Florida Market e seus efeitos sobre os componentes de crescimento, massa seca de raiz e parte aérea, observaram reduções significativas nos tratamentos em que a CE foi superior a $4,08 \mathrm{dS} \mathrm{m}^{-1}$.

Oliveira, Hernandez e Assis Junior (2008) afirmaram que as maiores limitações para o cultivo da berinjela estão relacionadas à baixa disponibilidade de água e de nutrientes no solo, durante seu ciclo, e a resposta desta espécie vegetal a fatores abióticos, tais como: salinidade e estresse hídrico; tem sido pouco estudadas.

O monitoramento das concentrações de nutrientes no solo exige determinações constantes, e a frequência destas determinações pode ser elevada se o ciclo da cultura for curto; desta forma, a utilização de extratores de solução do solo para esse monitoramento surge como uma alternativa viável para facilitar o manejo da fertirrigação e evitar possíveis processos de salinização do solo (DIAS et al., 2006; ELOI et al., 2007).

Com isso, este trabalho teve como objetivos: avaliar o efeito de diferentes níveis iniciais de salinidade do solo, causados por excesso de fertilizantes, sobre as variáveis fenológicas e de produção da berinjela em ambiente protegido; avaliar o uso de cápsulas porosas, funcionando como extratores de solução do solo, no auxílio ao manejo da fertirrigação em berinjela, visando o controle da salinização do solo; e averiguar se a manutenção da condutividade elétrica em um determinado nível promove incremento da produção, quando contrastada com o manejo tradicional da fertirrigação.

\section{MATERIAL E MÉTODOS}

$\mathrm{O}$ experimento foi conduzido em uma estufa plástica do Departamento de Engenharia de Biossistemas da Escola Superior de Agricultura "Luiz de Queiroz"USP, no município de Piracicaba-SP, situado nas coordenadas geográficas de $22^{\circ} 42^{\prime}$ de latitude sul e $47^{\circ} 38^{\prime}$ de longitude oeste, a uma altitude de $540 \mathrm{~m}$. Segundo a classificação de Koppen, o clima da região é do tipo Cwa, isto é, tropical úmido, com 3 meses mais secos (junho, julho e agosto), ocorrendo chuvas na primavera e verão e secas de inverno, apresentando temperatura média do mês mais quente superior a $22{ }^{\circ} \mathrm{C}$, e do mês mais frio inferior a $18^{\circ} \mathrm{C}$ (SENTELHAS, 1998).

$\mathrm{O}$ solo utilizado na referente pesquisa foi objeto de estudos em cultivos anteriores, no qual se tinha como fonte de variação o nível de condutividade elétrica (CE) da solução do solo, ocasionada pela adição de fertilizantes em ambiente protegido, sendo o mesmo classificado como Litossolo, textura franco-argilosa. O solo foi seco e peneirado em malha de $2 \mathrm{~mm}$; logo em seguida foi realizada uma amostragem em cada nível de salinidade para todas as repetições, visando obter uma amostra homogênea e proporcionando uma boa representatividade. As amostras foram submetidas ao preparo das pastas saturadas, com a finalidade de ranquear, de acordo com a condutividade elétrica, os níveis de salinidade existentes no solo em estudo ficando, portanto, divididos em 6 diferentes níveis de salinidade inicial do solo $(\mathrm{S} 1=1,3 ; \mathrm{S} 2=2,4 ; \mathrm{S} 3=3,6$; $\mathrm{S} 4=4,5 ; \mathrm{S} 5=5,6$ e S6 $=6,4 \mathrm{dS} \mathrm{m}^{-1}$ ) sendo aplicado dois 
manejos de fertirrigação: com controle da condutividade elétrica da solução do solo (M1), e o tradicional (M2), obedecendo a curva de absorção de nutrientes da cultura.

Os valores de CEs obtidos através do método da pasta saturada (extrato de saturação) foram relacionados com os valores de CEs medidos na solução do solo, coletada através de extratores de cápsula porosa, ajustando-se assim uma equação de estimativa da $\mathrm{CE}$ do extrato de saturação por meio da medida na solução coletada.

O delineamento estatístico adotado foi o de blocos casualizados completos, com quatro repetições, ficando os fatores estudados arranjados no esquema fatorial $6 \times 2$. Os 12 tratamentos propostos foram dispostos em 48 parcelas, ou seja, 48 vasos de 22,5 L espaçados de $0,9 \mathrm{~m}$ entre plantas e $1,5 \mathrm{~m}$ entre linhas; sendo que os dois primeiros e os dois últimos vasos de cada linha (bloco) funcionaram como bordaduras.

Utilizou-se o híbrido "Ciça" que possui como características, o grande vigor, a formação de frutos alongados de coloração vinho escura brilhante, e a lenta formação de sementes. As mudas de berinjela foram produzidas em bandejas de isopor de 128 células, preenchidas com substrato composto por material inerte e livre de patógenos. O transplantio foi realizado no dia 03 de junho de 2010, com uma muda por vaso, quando as mesmas apresentavam de três a quatro folhas definitivas, o que ocorreu por volta dos 30 dias após a semeadura.

Foi instalado um sistema de irrigação por gotejamento, utilizando emissores do tipo autocompensante, com vazão nominal de $3 \mathrm{Lh}^{-1}$, os quais foram previamente avaliados in loco, sob condições normais de operação, apresentando coeficiente de uniformidade de 97,3\%. Os gotejadores foram acoplados (on-line) às linhas de irrigação (tubos de polietileno $16 \mathrm{~mm}$ ), com registros instalados no início de cada linha, os quais permitiam aplicar o volume de água diferenciado por tratamento, condição excelente para o manejo M1, evitando possíveis contaminações salinas. O manejo de irrigação foi efetuado com base em dados de umidade do solo, obtidas indiretamente com tensiômetros, instalados a $0,15 \mathrm{~m}$ de profundidade, tomando por base a curva característica de retenção de água no solo.

A aplicação dos fertilizantes foi feita via água de irrigação, sendo os tratamentos diferenciados em função dos manejos de fertirrigação, M1 e M2. O manejo M2 baseou-se na marcha de absorção da cultura, calculada com base na exigência total para o ciclo da berinjela em g planta ${ }^{-1}$, obedecendo aos seguintes

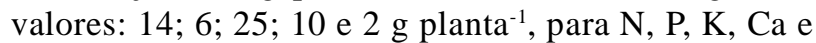
$\mathrm{Mg}$, respectivamente, (TRANI; CARRIJO, 2004).
A frequência da fertirrigação foi semanal, de acordo com o que foi sugerido anteriormente. Para os tratamentos referentes ao manejo M1, inicialmente, foi utilizada a mesma recomendação do manejo M2; entretanto, posteriormente, não foi preestabelecida a frequência nem a quantidade dos fertilizantes a serem aplicados. A fertirrigação só foi realizada quando a condutividade elétrica na solução do solo encontravase, em média $10 \%$ abaixo dos níveis iniciais de salinidade do solo, para cada tratamento. A quantidade de fertilizantes aplicada era aquela calculada para que a solução do solo recuperasse o nível de CE inicial $\left(1,3 ; 2,4 ; 3,6 ; 4,5 ; 5,6\right.$ e $\left.6,4 \mathrm{dS} \mathrm{m}^{-1}\right)$, sendo realizado a partir de uma curva que relacionava condutividade elétrica $\left(\mathrm{dS} \mathrm{m} \mathrm{m}^{-1}\right)$ com a concentração da solução $\left(\mathrm{mg} \mathrm{L}^{-1}\right)$, exposta na equação 1 .

$\mathrm{CEa}=\frac{\mathrm{CEf} \cdot \mathrm{Vv} \cdot \theta \mathrm{cc}-\mathrm{CEe} \cdot \mathrm{Vv}_{\mathrm{v}} \cdot \theta \mathrm{a}}{\mathrm{Vcc}}$

em que: CEa - condutividade elétrica da solução de fertirrigação a ser aplicada, $\mathrm{dS} \mathrm{m}^{-1}$; $\mathrm{CEf}$ - condutividade elétrica final da solução de sais fertilizantes na capacidade de campo, $\mathrm{dS} \mathrm{m} \mathrm{m}^{-1} ; \mathrm{Vv}$ - volume de solo contido no vaso, L; $\theta$ cc - umidade volumétrica do solo na capacidade de campo, $\mathrm{L} \mathrm{L}^{-1}$; $\mathrm{CEe}$ - condutividade elétrica da solução do solo medida por intermédio do uso de extrator de cápsula porosa, $\mathrm{dS} \mathrm{m} \mathrm{m}^{-1} ; \theta \mathrm{a}$ - umidade volumétrica atual, ou seja, imediatamente antes da fertirrigação, medida com tensímetro, L L L ${ }^{-1}$ Vcc - volume de solução necessário para o solo atingir a capacidade de campo, L.

\section{Foram realizadas as seguintes análises:}

- Produção de biomassa seca: medida no final do ciclo para folhas, frutos, hastes e raízes $\left(\mathrm{g} \mathrm{planta}^{-1}\right)$;

- Produção e componentes da produção: número de folhas por planta, número de frutos por planta e produção total de frutos $\left(\mathrm{g}\right.$ planta $\left.^{-1}\right)$;

- Índice de área foliar $\left(\mathrm{cm}^{2}\right)$ : avaliado no final do ciclo, por meio de um integrador eletrônico de área foliar, modelo LI-3100;

- Área foliar especifica $\left(\mathrm{cm}^{2} \mathrm{~g}^{-1}\right)$ : representa a razão entre área foliar total e a massa seca total das folhas.

As variáveis foram analisadas estatisticamente pelo teste de $\mathrm{F}$, desdobrando as análises, sempre que a interação foi significativa. $\mathrm{O}$ fator quantitativo, relativo aos níveis de salinidade inicial do solo, foi analisado estatisticamente por meio de regressão polinomial (linear e quadrática); já o fator manejo da fertirrigação foi analisado por meio de comparação de médias com base no teste de Tukey, a $5 \%$. 


\section{RESULTADOS E DISCUSSÃO}

A Figura 1 ilustra os valores de condutividade elétrica do extrato de saturação do solo, estimados por meio da correção dos valores de CE da solução, obtida com extratores. A Figura 1A representa o comportamento, em solo franco-argiloso dos valores de CEes, quando se pratica o manejo de fertirrigação com controle da condutividade elétrica (M1). A manutenção dos níveis iniciais da salinidade por meio do monitoramento da CEes estimada, permitiu manter os níveis iniciais, durante todo o ciclo da cultura.
A Figura 1B representa o comportamento dos valores de CEes estimada, quando se pratica o manejo tradicional de fertirrigação (M2) para a cultura da berinjela. Verifica-se que no manejo da fertirrigação tradicional ocorre um aumento da salinidade do solo para os tratamentos de níveis mais baixos (S1, S2 e S3) e um decréscimo da salinidade para os níveis mais elevados (S4, S5 e S6), com uma tendência de equilíbrio depois dos 80 DAT.

Assim sendo, para o manejo controlado (M1), verifica-se que ocorre uma orientação das linhas dos

Figura 1 - Valores de condutividade elétrica do extrato de saturação do solo, estimados a partir dos valores medidos na solução obtida por extratores, ao longo do ciclo da berinjela, para os dois manejos da fertirrigação propostos: manejo com controle da CE - M1 (A) e manejo tradicional - M2 (B)
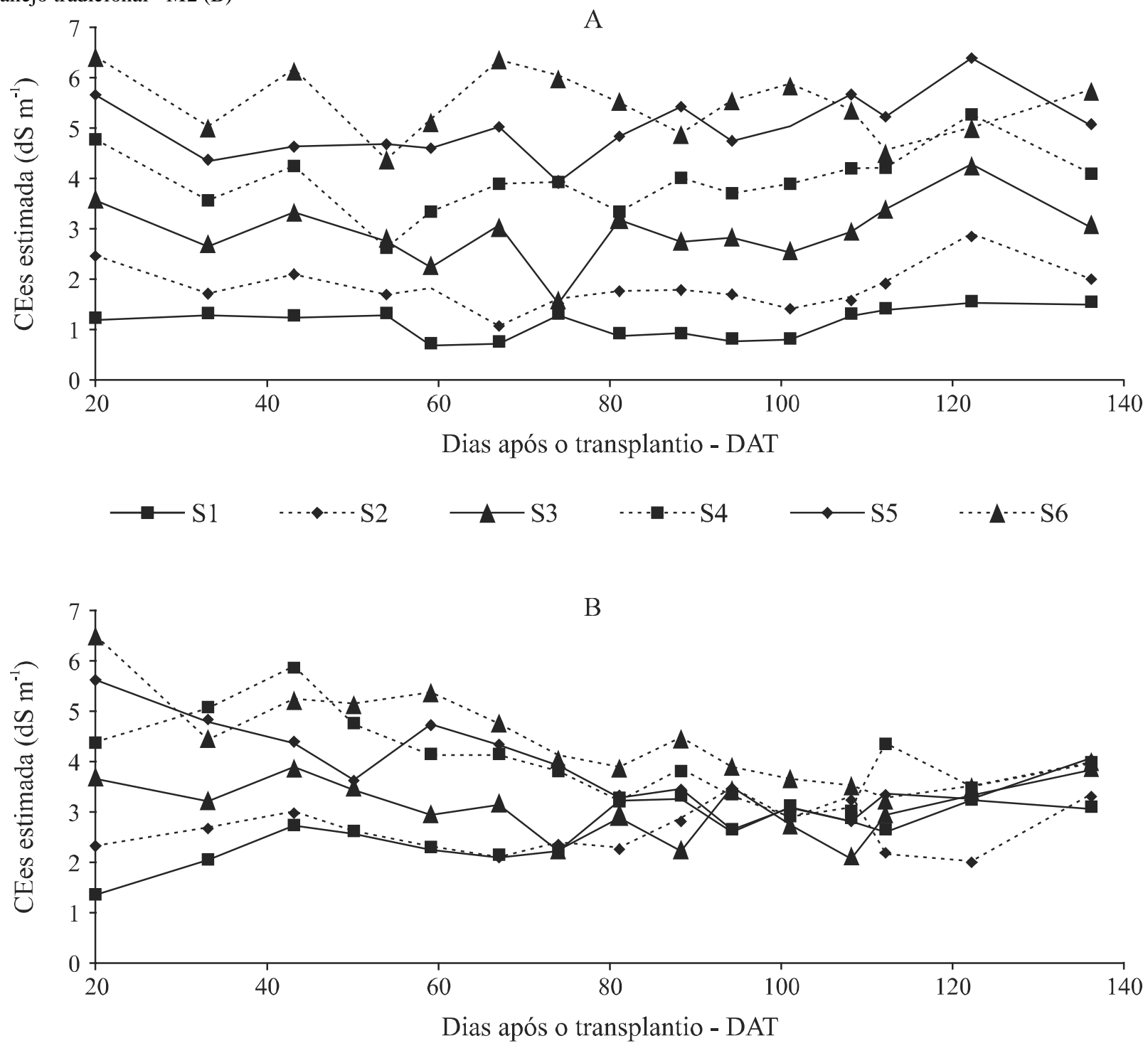

$\longrightarrow \mathrm{S} 1 \quad \cdots \cdot \cdots \mathrm{S} 2 \quad \longrightarrow \mathrm{S} 3 \quad \cdots-\cdots \mathrm{S} 4 \quad \longrightarrow \mathrm{S} 5 \quad \cdots \cdots \cdot \mathrm{S} 6$ 
níveis de CEes com menor número de cruzamentos; as linhas se mantiveram aproximadamente constantes ao longo do ciclo, comprovando assim a eficiência dos extratores de solução, o que torna possível sua utilização no auxilio do manejo da fertirrigação, podendo-se com isto, evitar o desperdício de fertilizantes e uma possível salinização dos solos cultiváveis.

Na Tabela 1 encontra-se o resumo da análise de variância para a variável matéria seca de folhas (MSF), matéria seca de haste (MSH), matéria seca de raiz (MSR), matéria seca total (MST) e número de folhas por planta (NF), ao longo do ciclo da berinjela, em função dos níveis de salinidade e dos manejos da fertirrigação. Verifica-se que houve efeito quadrático significativo $(\mathrm{p}<0,01)$, para as variáveis MSF, MSR e MST, verificando-se também um efeito quadrático significativo $(\mathrm{p}<0,05)$ para a variável $\mathrm{MSH}$, em função dos níveis de salinidade do solo, não sendo observado efeito significativo para a variável NF. Na interação entre os dois fatores estudados houve efeito significativo em nível de $\mathrm{p}<0,05$ apenas para a variável MSF.

As produções de matéria seca de folhas (MSF), matéria seca de haste (MSH), matéria seca de raiz (MSR) e matéria seca total (MST), seguiram modelos de resposta quadrática (Figura 2), com reduções nos valores dessas variáveis à medida que se aumentou o nível de salinidade na solução do solo acima de $3,3 \mathrm{dS} \mathrm{m}^{-1}$, assemelhandose com os resultados obtidos por Bosco et al. (2009), que observaram reduções significativas principalmente nos tratamentos em que a CE da solução nutritiva foi superior a $4,08 \mathrm{dS} \mathrm{m} \mathrm{m}^{-1}$, para os componentes de crescimento, produção da parte aérea e raiz de berinjela cultivar Florida Market cultivada hidroponicamente em ambiente protegido no Departamento Ciências do Solo da Universidade Federal do Ceará. Semelhantemente, Marques (2003), trabalhando com berinjela irrigada, com diferentes lâminas e concentrações de sais na água, observou menores valores de matéria seca nos tratamentos mais salinos. Por outro lado, Savvas e Lenz (2000) relataram que não houve efeito significativo do $\mathrm{NaCl}$ sobre o crescimento vegetativo de plantas de berinjela. Provavelmente, esses resultados ocorreram em função do menor nível de estresse, proporcionado pelo $\mathrm{NaCl}$ imposto no referido trabalho, ou seja, uma salinidade bem inferior àquelas avaliadas no presente ensaio.

A explicação mais aceita para a inibição do crescimento pelo sal é a redução do potencial osmótico da solução de cultivo, podendo também haver toxicidade iônica, desequilíbrios nutricionais, ou ambos, devido à acumulação excessiva de certos íons nos tecidos vegetais (YOKOI; BRESSAN; HASEGAWA, 2002). Além disso, segundo Flowers (2004) e Munns (2002), as plantas fecham os estômatos para reduzir as perdas de água por transpiração, resultando em uma menor taxa fotossintética, o que constitui uma das causas da redução do crescimento das espécies glicófiticas sob condições de estresse salino.

Estes resultados estão de acordo com os encontrados por Souza, Alcantara Junior e Amorim (2007), que descrevem o efeito negativo imediato da salinidade sobre a produção da massa seca da parte aérea (caule e folhas),

Tabela 1 - Resumo da análise de variância e médias das massas secas, em g planta-1 ${ }^{-1}$ de folhas (MSF), de haste (MSH), de raízes (MSR) e total (MST), e número de folhas planta-1 $(\mathrm{NF})$, para a cultura da berinjela, em função dos níveis de salinidade e dos manejos da fertirrigação

\begin{tabular}{|c|c|c|c|c|c|c|}
\hline \multirow{2}{*}{ Fonte de variação } & \multirow{2}{*}{ GL } & \multicolumn{5}{|c|}{ Estatística F } \\
\hline & & MSF & $\mathrm{MSH}$ & MSR & MST & NF \\
\hline Salinidade (S) & 5 & $16,09^{\mathrm{ns}}$ & $1,72^{\mathrm{ns}}$ & $3,70 * *$ & $9,37 * *$ & $0,12^{\text {ns }}$ \\
\hline Linear & - & $0,43^{\mathrm{ns}}$ & $1,70^{\mathrm{ns}}$ & $0,69^{\text {ns }}$ & $28,93 * *$ & $0,04^{\mathrm{ns}}$ \\
\hline Quadrática & - & $65,78 * *$ & $6,40 *$ & $14,80 * *$ & $13,21 * *$ & $0,08^{\mathrm{ns}}$ \\
\hline Manejo (M) & 1 & $2,58^{\mathrm{ns}}$ & $12,31 * *$ & $1,84^{\mathrm{ns}}$ & $7,38 *$ & $0,46^{\text {ns }}$ \\
\hline $\mathrm{S} \times \mathrm{M}$ & 5 & $3,33 *$ & $0,40 \mathrm{~ns}$ & $1,36^{\mathrm{ns}}$ & $0,32^{\mathrm{ns}}$ & $1,23^{\text {ns }}$ \\
\hline Bloco & 3 & $0,51^{\mathrm{ns}}$ & $3,67 *$ & $1,00^{\mathrm{ns}}$ & $0,76^{\mathrm{ns}}$ & $5,38^{\mathrm{ns}}$ \\
\hline Média geral & - & 115,3 & 158,29 & 78,57 & 458,85 & 174,52 \\
\hline \multirow[t]{2}{*}{$\mathrm{CV}(\%)$} & - & 7,16 & 12,41 & 17,35 & 8,36 & 14,73 \\
\hline & & \multicolumn{5}{|c|}{ Valores Médios\# } \\
\hline M1 & - & $117,35 \mathrm{a}$ & $148,34 b$ & $75,90 \mathrm{a}$ & $443,80 b$ & $172,00 \mathrm{a}$ \\
\hline M2 & - & $113,52 \mathrm{a}$ & $168,24 a$ & $81,24 a$ & $473,90 \mathrm{a}$ & $177,08 \mathrm{a}$ \\
\hline
\end{tabular}

\# Médias seguidas de mesma letra na coluna não diferem entre si, em nível de 0,05 de probabilidade, pelo teste de Tukey, ns Não significativo em nível de 0,05 de probabilidade, pelo teste $\mathrm{F}, *$; ** Significativo em nível de 0,05 e 0,01 de probabilidade, respectivamente, pelo teste $\mathrm{F}$ 
Figura 2 - Diagramas de dispersão e equação de ajuste, para ambos os manejos da fertirrigação, relativos à matéria seca de folhas (MSF) e matéria seca de raiz (MSR) (A e C), respectivamente; e para os manejos controlado e tradicional da fertirrigação, relativos à matéria seca de haste (MSH) e a matéria seca total da planta (MST), (B e D), respectivamente
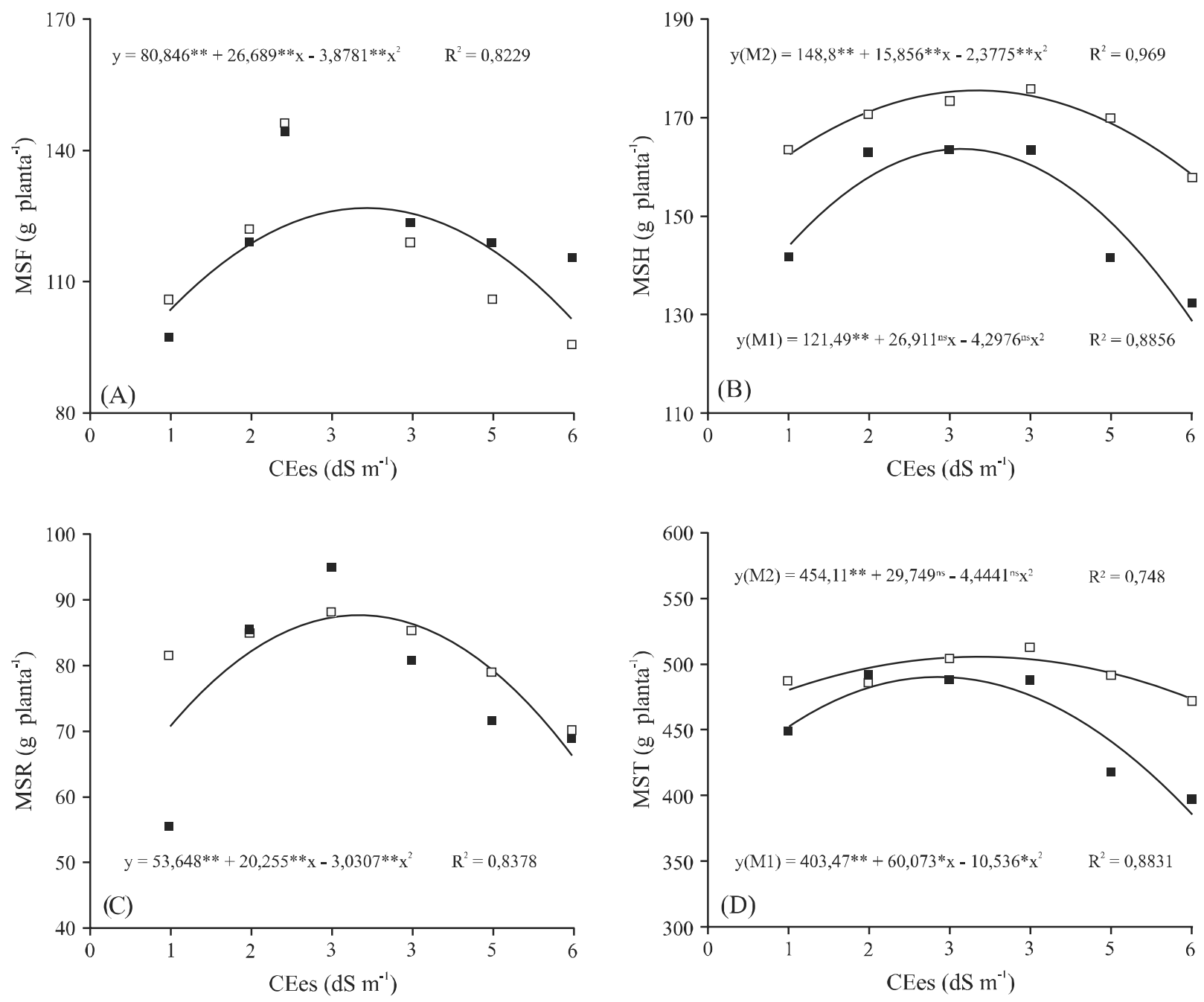

M1 $\square \mathrm{M} 2$

e do sistema radicular, em Physalis angulata L, planta da mesma família da berinjela, conhecida em algumas regiões como camapú ou camapum.

Na Tabela 2, encontra-se a média da variável matéria seca de folhas (MSF), referente à interação entre os fatores salinidade do solo e manejo de fertirrigação. Os maiores valores de MSF foram obtidos nos dois maiores níveis de salinidade dentro do manejo M1, quando comparado ao M2, que apresentou seu maior valor no nível S3, e os menores valores de MSF foram obtidos no nível de salinidade S1 para o manejo M1, e em S6 para M2, porém não diferindo em S1 e S5, $\operatorname{logo}$ não verificando-se diferença significativa para os demais níveis dentro de cada manejo (Tabela 2).
Tabela 2 - Valores médios da variável matéria seca da folha em gramas por planta (MSF), para os dois manejos de fertirrigação propostos e os níveis de salinidade do solo

\begin{tabular}{|c|c|c|}
\hline \multirow{2}{*}{ Níveis de salinidade } & \multicolumn{2}{|c|}{ MSF } \\
\hline & M1 & M2 \\
\hline $\mathrm{S} 1$ & $96,79 \mathrm{Ab}$ & $105,41 \mathrm{Abc}$ \\
\hline S2 & $118,66 \mathrm{Aa}$ & 121,71 Aab \\
\hline S3 & $132,10 \mathrm{Aa}$ & $134,00 \mathrm{Aa}$ \\
\hline S4 & $123,18 \mathrm{Aa}$ & $119,00 \mathrm{Aab}$ \\
\hline S5 & $118,21 \mathrm{Aa}$ & $105,75 \mathrm{Bbc}$ \\
\hline S6 & $115,17 \mathrm{Aa}$ & $95,25 \mathrm{Bc}$ \\
\hline
\end{tabular}

*Médias seguidas da mesma letra maiúscula nas linhas, e minúsculas nas colunas, não diferem entre si pelo teste de Tukey em nível de 0,05 de probabilidade 
Na Tabela 3 encontra-se o resumo da análise de variância para as variáveis número de frutos por planta (NFR), matéria fresca de frutos (MFFR), matéria seca de frutos (MSFR), índice de área foliar (IAF) e área foliar específica (AFESP), medidas ao longo do ciclo da berinjela, em função dos níveis de salinidade e dos manejos da fertirrigação. Verifica-se que houve efeito quadrático significativo $(\mathrm{p}<0,01)$ para as variáveis MFFR e IAF, e efeito quadrático significativo $(\mathrm{p}<0,05)$ para a variável NFR, em função dos níveis de salinidade do solo. As variáveis NFR, MFFR e MSFR apresentaram um ajuste linear significativo ( $\mathrm{p}<0,01$ ), não foi observado efeito significativo para a variável AFESP. A interação entre os dois fatores estudados só foi significativa em nível de $\mathrm{p}<0,05$ para a variável NFR.

Em relação à variável número de frutos por planta (NFR) verifica-se que houve efeito quadrático significativo $(\mathrm{p}<0,05)$ (Figura 3A); no manejo M1 fica evidenciado o aumento do número de frutos com o aumento dos níveis de salinidade. Já a matéria fresca de frutos (MFFR) (Figura 3B) e a matéria seca de frutos (MSFR) (Figura 3C) decresceram linearmente com o aumento da salinidade sugerindo que os níveis mais altos de salinidade produzem mais frutos, porém o rendimento final da cultura (g planta ${ }^{-1}$ ) é afetado negativamente.

A produtividade total ou matéria fresca de frutos (MFFR) (g planta $^{-1}$ ) pode ser explicada por um modelo linear, indicando que houve um decréscimo na produtividade, à medida que se aumentava os níveis de condutividade elétrica da solução do solo (Figura 3B).
O ponto de maior produtividade foi obtido com o nível de condutividade de $1,3 \mathrm{dS} \mathrm{m}^{-1}$, e que equivaleu a uma produtividade média observada de $1.323 \mathrm{~g} \mathrm{planta}^{-1}$.

O aumento da concentração salina da solução do solo provocou também declínio na área foliar das plantas. A redução dessa variável (Figura 3D) ajustouse a um modelo quadrático, com o valor máximo para salinidade de aproximadamente $4,5 \mathrm{dS} \mathrm{m} \mathrm{m}^{-1}$. Tendências semelhantes foram apresentadas por Folegatti e Blanco (2000), ao avaliarem o crescimento foliar da berinjela e do pepino irrigados com água salina.

$\mathrm{Na}$ Tabela 4, encontram-se as médias do número de frutos (NFR) referentes ao desdobramento da interação entre os fatores salinidade do solo e manejo de fertirrigação. Verificando-se diferenças significativas, tanto entre os níveis de salinidade do solo, quanto entre os manejos de fertirrigação. O NFR mostrou-se significativamente superior no manejo M2 para os três primeiros níveis de salinidade, sendo o maior e menor valor observado no quarto e primeiro nível de salinidade no manejo M2 e M1, respectivamente (Tabela 4).

Segundo os resultados obtidos para a variável matéria fresca de frutos (Figura 3B), verifica-se que ocorre uma redução na produtividade da berinjela na ordem de $8,65 \%$ para o incremento de $1 \mathrm{dS} \mathrm{m}^{-1}$ na salinidade do solo, acima da salinidade limiar, que foi de $1,71 \mathrm{dS} \mathrm{m}^{-1}$; valores estes bem próximo dos observados por Unlukara et al. (2008) ao estudar o efeito da salinidade sobre a berinjela na região de Tokat, Turquia, verificaram queda no rendimento de $4,4 \%$

Tabela 3 - Resumo da análise da variância e médias do número de frutos por planta (NFR), matéria fresca de frutos (g planta-1 $)$ (MFFR), matéria seca de frutos $\left(\mathrm{g}\right.$ planta $\left.{ }^{-1}\right)$ (MSFR), índice de área foliar $\left(\mathrm{cm}^{2}\right)$ (IAF), área foliar específica $\left(\mathrm{cm}^{2} \mathrm{~g}^{-1}\right)$ (AFESP), para a cultura da berinjela, em função dos níveis de salinidade e dos manejos de fertirrigação

\begin{tabular}{|c|c|c|c|c|c|c|}
\hline \multirow{2}{*}{ Fonte de variação } & \multirow{2}{*}{ GL } & \multicolumn{5}{|c|}{ Estatística F } \\
\hline & & NFR & MFFR & MSFR & IAF & AFESP \\
\hline Salinidade (S) & 5 & $8,77 * *$ & $33,68 * *$ & $18,11 * *$ & $4,28 * *$ & $0,50^{\text {ns }}$ \\
\hline Linear & - & $37,61 * *$ & $157,71 * *$ & $86,37 * *$ & $0,19^{\text {ns }}$ & $0,61^{\mathrm{ns}}$ \\
\hline Quadrática & - & $4,58 *$ & $8,83 * *$ & $2,80^{\mathrm{ns}}$ & $20,56 * *$ & $0,12^{\mathrm{ns}}$ \\
\hline Manejo (M) & 1 & $28,33 * *$ & $3,35^{\mathrm{ns}}$ & $2,92^{\mathrm{ns}}$ & $3,38^{\mathrm{ns}}$ & $0,71^{\mathrm{ns}}$ \\
\hline$S \times M$ & 5 & $3,54 *$ & $2,41^{\mathrm{ns}}$ & $0,49^{\mathrm{ns}}$ & $0,51^{\mathrm{ns}}$ & $0,53^{\mathrm{ns}}$ \\
\hline Bloco & 3 & $0,53^{\text {ns }}$ & $0,74^{\mathrm{ns}}$ & $0,93^{\mathrm{ns}}$ & $0,24^{\mathrm{ns}}$ & $0,42^{\mathrm{ns}}$ \\
\hline Média geral & - & 22,22 & 789,29 & 106,55 & 19676,66 & 170,98 \\
\hline $\mathrm{CV}(\%)$ & - & 13,30 & 16,18 & 16,57 & 13,63 & 14,32 \\
\hline Manejo (M) & & \multicolumn{5}{|c|}{ Valores Médios\# } \\
\hline M1 & - & $19,95 b$ & $764,18 \mathrm{a}$ & $102,19 \mathrm{a}$ & $18964,84 a$ & $174,09 a$ \\
\hline M2 & - & $24,50 \mathrm{a}$ & $832,40 a$ & $110,90 \mathrm{a}$ & $20388,49 a$ & $163,88 \mathrm{a}$ \\
\hline
\end{tabular}

\#Médias seguidas de mesma letra na coluna não diferem entre si, em nível de 0,05 de probabilidade, pelo teste de Tukey, ${ }^{\text {ns }}$ Não significativo em nível de 0,05 de probabilidade, pelo teste $\mathrm{F}^{* ; * *}$ Significativo em nível de 0,05 e 0,01 de probabilidade, respectivamente, pelo teste $\mathrm{F}$ 
Figura 3 - Diagramas de dispersão e equação de ajuste, para ambos os manejos da fertirrigação, relativos à matéria fresca de fruto (MFFR), e matéria seca de fruto (MSFR), (B e C), respectivamente; e para os manejos controlado e tradicional da fertirrigação, relativos à número de fruto, (NFR) e o índice de área foliar, (A e D), respectivamente
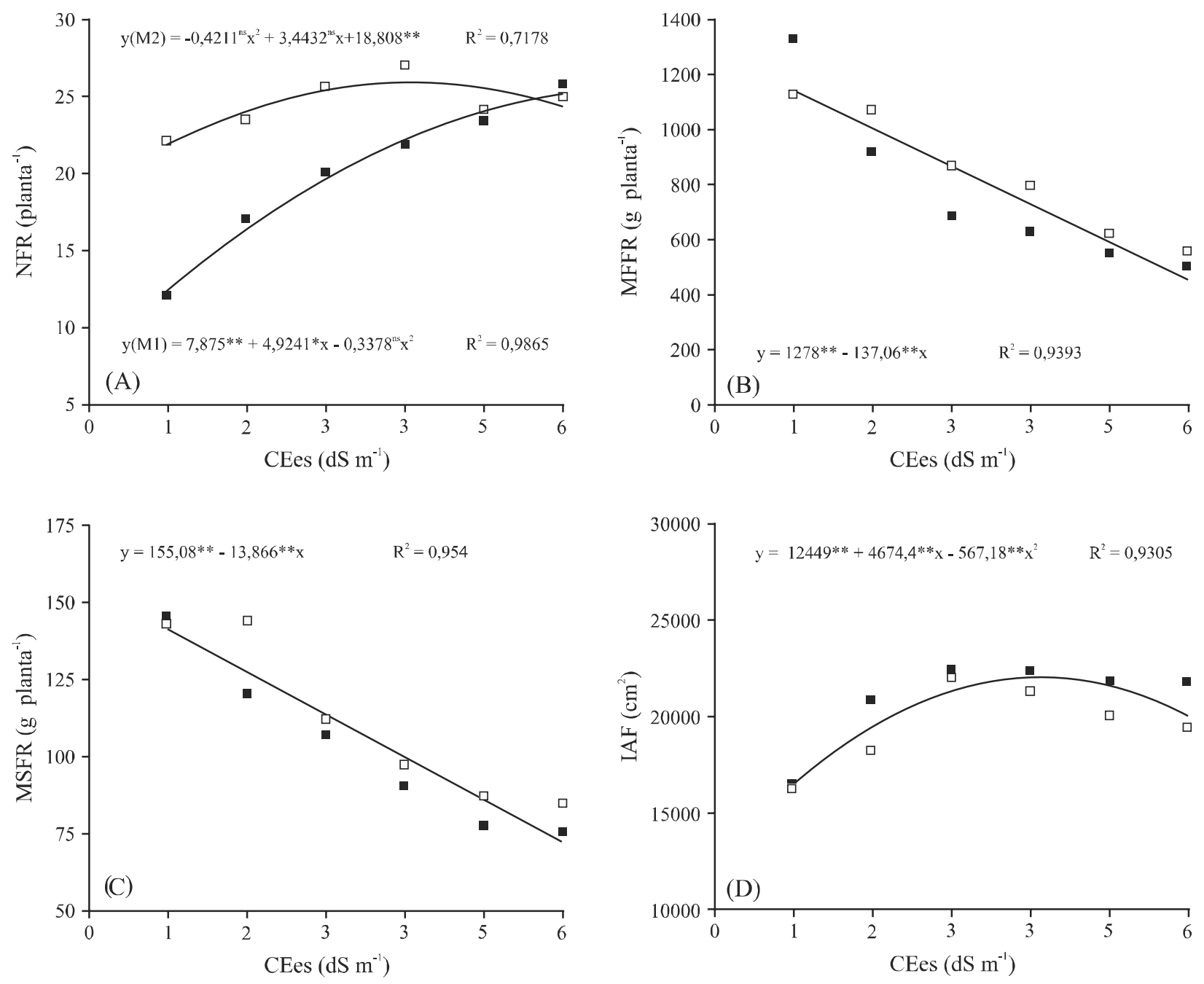

M1 $\square \mathrm{M} 2$

Tabela 4 - Valores médios da variável número de frutos por planta (NFR), para os dois manejos de fertirrigação e os diferentes níveis de salinidade do solo

\begin{tabular}{lll}
\hline \multirow{2}{*}{ Níveis de salinidade } & \multicolumn{2}{c}{ NFR } \\
\cline { 2 - 3 } & M1 & M2 \\
\hline S1 & $12,00 \mathrm{Bc}$ & $22,00 \mathrm{Aa}$ \\
S2 & $17,00 \mathrm{Bbc}$ & $23,50 \mathrm{Aa}$ \\
S3 & $20,00 \mathrm{Bab}$ & $25,50 \mathrm{Aa}$ \\
S4 & $21,75 \mathrm{Aab}$ & $27,00 \mathrm{Ab}$ \\
S5 & $23,25 \mathrm{Aab}$ & $24,00 \mathrm{Aa}$ \\
S6 & $25,75 \mathrm{Aa}$ & $25,00 \mathrm{Aa}$ \\
\hline
\end{tabular}

*Médias seguidas da mesma letra maiúscula nas linhas, e minúsculas nas colunas, não diferem entre si, pelo teste de Tukey em nível de 0,05 de probabilidade para cada aumento unitário de condutividade elétrica da água de irrigação a partir de $1,5 \mathrm{dS} \mathrm{m}^{-1}$.

Os resultados de salinidade limiar encontrados, também estão de acordo com os obtidos por Maas e Hoffman (1977), que apesar de não mencionarem berinjela em sua pesquisa, citam $1,5 \mathrm{dS} \mathrm{m}^{-1}$ para o pimentão e 2,5 $\mathrm{dS} \mathrm{m}^{-1}$ para o tomate, que também pertencem à família das Solanáceas.

\section{CONCLUSÕES}

Considerando as condições em que o experimento foi desenvolvido, os resultados obtidos permitiram concluir que: 
1. Os níveis mais elevados de salinidade do solo, proporcionados pela adição de sais fertilizantes afetaram o índice de área foliar e as massas secas de hastes, folhas e raízes;

2. Os níveis iniciais de salinidade do solo, provocados pela aplicação excessiva de adubos em cultivos anteriores, afetaram a produção e os componentes da produção para a cultura da berinjela;

3. Não foi possível detectar diferenças significativas na produtividade da berinjela que pudessem ser atribuídas aos dois tipos de manejo de fertirrigação utilizados;

4. A redução na produção da cultura da berinjela em estufa foi em média de $8,65 \%$ por incremento de $1 \mathrm{dS}$ $\mathrm{m}^{-1}$ na salinidade do solo, acima da salinidade limiar, que foi de $1,71 \mathrm{dS} \mathrm{m} \mathrm{m}^{-1}$.

\section{REFERÊNCIAS}

ANTONINI, A. C. C. et al. Capacidade produtiva de cultivares de berinjela. Horticultura Brasileira, v. 20, n. 04, p. 646-648, 2002.

BOSCO, M. R. O. et al. Efeito do $\mathrm{NaCl}$ sobre o crescimento, fotossíntese e relações hídricas de plantas de berinjela. Revista Ceres, v. 56, n. 03, p. 296-302, 2009.

CARDOSO, M. O. et al. Eggplant growth as affected by bovine manure and magnesium thermophosphate rates. Scientia Agricola, v. 65, n. 01, p. 77-86, 2008.

DIAS, N. S. et al. Salinidade e manejo da fertirrigação em ambiente protegido. I: efeitos sobre o crescimento do meloeiro. Irriga, v. 11, n. 02, p. 208-218, 2006.

ELOI, W. M. et al. Níveis de salinidade e manejo da fertirrigação sobre características do tomateiro cultivado em ambiente protegido. Revista Brasileira de Ciências Agrárias, v. 02, n. 01, p. 83-89, 2007.

FILGUEIRA, F. A. R. Novo manual de olericultura: agrotecnologia moderna na produção e comercialização de hortaliças. Viçosa: UFV, 2000. 402 p.

FLOWERS, T. J. Improving crop salt tolerance. Journal of Experimental Botany, v. 55, n. 396, p. 307-319, 2004.

FOLEGATTI, M. V.; BLANCO, F. F. Desenvolvimento vegetativo do pepino enxertado irrigado com água salina. Scientia Agricola, v. 57, n. 03, p. 451-457, 2000.

GONÇALVES, M. da C. R. et al. Modesto efeito hipolipemiante do extrato seco de berinjela (Solanum melongena L.) em mulheres dislepidemias, sob controle nutricional. Revista Brasileira de Farmacognosia, v. 16, p. 656-663, 2006. Suplemento.

MAAS, E. V.; HOFFMAN, G. J. Crop salt tolerance - Current Assessment. Journal of Irrigation and Drainage Division, v. 103, n. 02, p. 115-134, 1977.

MAGGI, M. F. et al. Produção de variedades de alface sob diferentes potenciais de água no solo em ambiente protegido. Irriga, v. 11, n. 03, p. 415- 427, 2006.

MARQUES, D. C. Produção de berinjela (Solanum melongena L.) irrigada com diferentes lâminas e concentrações de sais na água. 2003. 55 f. Dissertação (Mestrado em Fitotecnia) Universidade Federal de Lavras, Lavras, 2003.

MOURA, D. C. M.; CARVALHO, J. A.; GOMES, L. A. A. Evapotranspiração da cultura da berinjela irrigada com diferentes concentrações de sais na água. Engenharia Agrícola, v. 15, p. 1-6, 2004.

MUNNS, R. Comparative physiology of salt and water stress. Plant, Cell and Environment, v. 25, n. 02, p. 239-250, 2002.

OLIVEIRA, A. B. de; HERNANDEZ, F. F. F.; ASSIS JUNIOR, R. N. de. Pó de coco verde, uma alternativa de substrato na produção de mudas de berinjela. Revista Ciência Agronômica, v. 39, n. 01, p. 39-44, 2008.

SAVVAS D.; LENZ F. Effects of $\mathrm{NaCl}$ or nutrient-induced salinity on growth, yield, and composition of eggplants grown in rockwool. Scientia Horticulturae, v. 84, n. 01/02, p. 37-47, 2000.

SENTELHAS, P. C. Estimativa diária da evapotranspiração de referência com dados de estação meteorológica convencional e automática. 1998. 97 f. Tese (Doutorado em Irrigação e Drenagem) - Escola Superior de Agricultura "Luiz de Queiroz", Universidade de São Paulo, Piracicaba, 1998.

SOUZA, N. K. R.; ALCANTARA JÚNIOR, J. P.; AMORIM, S. M. C. Efeito do estresse salino sobre a produção de fitomassa em Physalis angulata L. (Solanaceae). Revista Acadêmica, v. 05, n. 04, p. 379-384, 2007.

TRANI, P. E.; CARRIJO, O. A. Fertirrigação em hortaliças. Campinas: Instituto Agronômico, 2004. 58 p. (Boletim Técnico IAC, 196).

UNLUKARA, A. et al. Effects of salinity on eggplant (Solanum Melongena L.) growth and evapotranspiration. Journal of Irrigation and Drainage, v. 59, n. 01, p. 203214, 2008.

YOKOI, S.; BRESSAN, R. A.; HASEGAWA, P. M. Salt stress tolerance of plants. JIRCAS Working Report, v. 23, n. 01, p. 25-33, 2002. 